\title{
Annular atrophic lichen planus
}

INSERM

\section{Source}

INSERM. (1999). Orphanet: an online rare disease and orphan drug data base. Annular atrophic lichen planus. ORPHA:254411

Annular atrophic lichen planus (LP) is a rare variant of cutaneous lichen planus (see this term) characterized by both annular and atrophic LP (see these terms) features in the same lesion. 